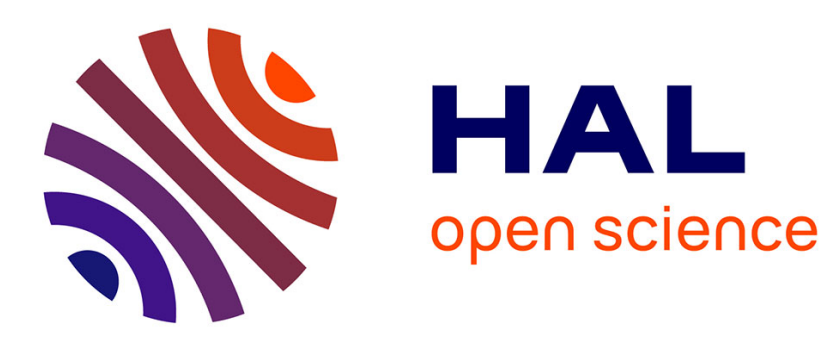

\title{
EL2-related studies in irradiated and implanted GaAs
}

G. Guillot

\section{To cite this version:}

G. Guillot. EL2-related studies in irradiated and implanted GaAs. Revue de Physique Appliquée, 1988, 23 (5), pp.833-846. 10.1051/rphysap:01988002305083300 . jpa-00245887

\section{HAL Id: jpa-00245887 https://hal.science/jpa-00245887}

Submitted on 1 Jan 1988

HAL is a multi-disciplinary open access archive for the deposit and dissemination of scientific research documents, whether they are published or not. The documents may come from teaching and research institutions in France or abroad, or from public or private research centers.
L'archive ouverte pluridisciplinaire HAL, est destinée au dépôt et à la diffusion de documents scientifiques de niveau recherche, publiés ou non, émanant des établissements d'enseignement et de recherche français ou étrangers, des laboratoires publics ou privés. 
Classification

Physics Abstracts

$61.70-61.80-71.55-72.20$

\title{
EL2-related studies in irradiated and implanted GaAs
}

\author{
G. Guillot \\ Laboratoire de Physique de la Matière (associé au CNRS), Institut National des Sciences Appliquées de Lyon, \\ 20 avenue Albert Einstein, 69621 Villeurbanne Cedex, France
}

(Reçu le 15 juillet 1987, accepté le 24 septembre 1987)

\begin{abstract}
Résumé. - Le donneur profond EL2 est un défaut très important par le rôle qu'il joue dans la compensation du matériau GaAs semi-isolant non dopé. La connaissance de sa structure exacte devient de plus en plus nécessaire. Nous présentons une revue des résultats expérimentaux concernant la création artificielle de EL2 par irradiation (électrons, neutrons) et également par implantation ionique avec et sans recuit. Ces études ont fortement contribué à spécifier la nature de EL2 à savoir un défaut intrinsèque complexe à base d'un arsenic antisite $\mathrm{As}_{\mathrm{Ga}}\left(\mathrm{As}_{\mathrm{Ga}}+\mathrm{X}\right)$. Nous soulignons de nouveaux concepts tels que les transitions par sauts dues au tunnelling des électrons entre défauts profonds proposées pour interpréter les résultats obtenus sur les matériaux implantés et irradiés aux neutrons. Nous discutons également les principaux résultats de ces expériences de créations artificielles en fonction des plus récents modèles proposés pour EL2 à ce jour.
\end{abstract}

\begin{abstract}
The midgap donor level EL2 is a very important defect because of the role it plays in the compensation of undoped semi-insulating GaAs. The knowledge of the exact EL2 structure becomes of even greater prime importance. We present here a review of the experimental results concerning artificial EL2 creation by electron and neutron irradiation and also ion implantation followed or not by annealing. These studies have greatly contributed in specifying the nature of EL2 namely a complex intrinsic defect with an arsenic antisite as a core $\left(\mathrm{As}_{\mathrm{Ga}}+\mathrm{X}\right)$. We point out some new concepts such as hopping transitions due to interdefect electron tunnelling which have been tentatively proposed to account for observations in implanted and neutron irradiated samples. We also discuss the main results of these artificial creation experiments as a function of the recent models proposed for EL2 up to the present day.
\end{abstract}

\section{Introduction.}

The defect designated as EL2 is very important technologically because the state-of-the art method to grow semi-insulating (SI) GaAs uses the liquidencapsulated Czochralski process with the As vapor pressure controlled so as to introduce a concentration of the EL2 deep donor levels sufficient to compensate the residual carbon acceptors. Because of this technological importance - it is doubtless that its identification would lead to rapid progress in the technology of SI GaAs - and because of its still mysterious and fascinating property of metastability [1-3] -under a low-temperature photoexcitation it transforms into a different configuration, EL2 has been extensively studied for the past five years and its properties have been the subject of several recent review papers [4-7]. As a final result, this metastability which manifests by photoquenching behaviour of photocapacitance [3], photoconductivity [8], elec- tron paramagnetic resonance (EPR) [9], photoluminescence and optical absorption $[10,11]$ has become a kind of specific fingerprint for the presence of EL2.

For a few years now considerable effort has been devoted to the question of identifying the precise atomic identity of EL2. Despite numerous experiments in many laboratories, its identity and structure have not been completely elucidated [7]. However, there is a large consensus associating the EL2 with the $\mathrm{As}_{\mathrm{Ga}}$ antisite defect $[5,7]$ based mainly on stœchiometric correlations $[6,12]$ and on EPR observations showing similar photoquenching behaviour of both EL2 and the $\mathrm{As}_{\mathrm{Ga}}$ EPR signal $[9,13]$.

One powerful way to obtain defect identification is to try to create artificially the defect by irradiation or implantation and to study it by a combination of complementary techniques to get its electrical and optical properties (deep-level transient spectroscopy (DLTS), Hall effect, luminescence, optical absorp- 
tion) and its microscopic structure (EPR). This last method has been proved to be very powerful for point defect identification in Si. Consequently, creating the defect by irradiation is a very important step in its identification since it can be concluded if the studied defect is impurity related or not, a primary or a more complex defect. This procedure has been applied to EL2 defect in GaAs and we will see that, even if the firm identification of EL2 is not completely finished, it has given very important conclusions in this research field. Furthermore these studies can provide important data for optimizing the annealing conditions for the recovered from the lattice damage associated with ion implantation techniques.

Part 2 will be devoted to the detailed investigations of the artificial creation of EL2 by particle irradiations : ions, neutrons and electrons respectively. A discussion of the possible origin of EL2 will be made in part 3 in view of all the data presented and of the recent proposed models for EL2.

\section{Artificial creation of EL2.}

Defects can be introduced mainly by ion implantation, fast neutron and fast electron irradiation. Electron bombardment is expected to produce simpler defects such as single vacancies, interstitials and Frenckel defect pairs [14]. The transformation of these primary defects can be followed when they become mobile and interact which each other or with the impurities present in the samples. For heavy ion implantation each impinging ion can impact a larger portion of its kinetic energy to lattice atoms than electrons. In turn, the lattice atom displaced during the initial collision can have considerable kinetic energy and can generate a cascade of defects in a very small volume of the bombarded material creating clusters of defects. Lang [15] has reported a comparison between DLTS spectra on $\mathrm{n}-\mathrm{GaAs}$ irradiated by high energy particles of different types (electrons, protons, $\mathrm{He}^{+}$and $\mathrm{O}^{+}$). The DLTS spectra obtained were mainly different for the two deepest levels. The general trend is towards a broader DLTS peak as the mass of the high energy particle increases or as defect clusters are formed.

Fast neutron irradiation are of particular interest since without introduction of new species, one can simulate implantation conditions within the bulk of a sample since the primary knock-on energy of a lattice atom hit by an incoming $1-2 \mathrm{MeV}$ neutron is about $50 \mathrm{keV}$ which is an energy typical for implantations. DLTS spectra of fast neutron irradiated materials [16] look like those obtained in heavy ion implanted samples and are different from those obtained in proton-irradiated samples. This seems surprising since protons and neutrons have equal masses but one must remember that contrary to protons, neutrons interact only through nuclear collisions with lattice atoms. Consequently, neutrons generate defect clusters more efficiently than protons.

2.1 CREATION OF EL2 By ION IMPLANTATION. Jervis et al. [17] were the first to report an artificial creation of a level which was probably EL2 in LPE material implanted with a low dose of $\mathrm{Si}$ through a $\mathrm{Si}_{3} \mathrm{~N}_{4}$ cap and annealed at $860^{\circ} \mathrm{C}$. One should remember here that the undoped GaAs LPE materials are completely free of native electron traps like EL2. However, in this first experiments, the EL2 like trap concentration was very small and the photocapacitance quenching of EL2 at low temperature was not checked.

Latter on Ikoma et al. [18] and Taniguchi et al. $[19,20]$ observed deep levels with DLTS signatures similar to EL2 created with a rather high concentration by implanting LPE n-GaAs layers with As, $\mathrm{Ga}$ and $\mathrm{O}$ ions and subsequent annealing for $15 \mathrm{~min}$ at $600{ }^{\circ} \mathrm{C}$. In fact, these authors observed slight differences mainly in the photoionization threshold energy between the trap created by oxygen implantation compared to the known optical properties of EL2 and to the level created by other ions. So they proposed two types of EL2 levels : one associated with oxygen and the other not associated [19]. In fact, in these pioneering works the authors did not verify the photoquenching effect and based their identification only on the similarity between the thermal signature of levels. There remained some uncertainty as to the identification with EL2.

Latter on Martin et al. [21] performed same sort of experiments on bulk and LPE materials. An annealing treatment at $860^{\circ} \mathrm{C}$ for $15 \mathrm{~min}$ under $\mathrm{Si}_{3} \mathrm{~N}_{4}$ was carried out on the bulk material, prior to the implantation, in order to reduce within the first micron below the surface the initial concentration of EL2. Oxygen, neon and boron have been implanted at the same dose $\left(10^{12} \mathrm{~cm}^{-2}\right)$ but at different energies in order to have the same projected range $\left(R_{\mathrm{p}}=1540 \AA\right)$. The samples were then annealed at $600{ }^{\circ} \mathrm{C}$ for $15 \mathrm{~min}$. Two electron traps are detected in large concentration in the implanted region at the position expected for the levels EL3 and EL2. Exactly the same data have been recorded on samples implanted with boron, oxygen and neon, the concentration of DLTS peaks increasing nearly with the mass of the implanted atom [21].

This established definitively that the two observed peaks correspond to intrinsic lattice defects and are not related to implanted species or to impurities.

Experimental evidence was given of the EL2 creation in bulk GaAs from the classical photoquenching effect observed on the photocapacitance transient [21]. Surprisingly, on the LPE sample no photoquenching effect can be detected in the capaci- 
tance transient under $1.06 \mu \mathrm{m}$ excitation. In fact, this was explained not by a fundamental effect possibly related to different concentrations of native defects in LPE compared to bulk materials but by the leakage reverse current of the LPE schottky barriers which was too large and which prevents the electron emptying of EL2 and thus the formation of the metastable state [7]. However, the electron emission rate of the level created in LPE and bulk materials was found to vary with electric field and temperature in a very similar way to that known for the EL2 level [7]. Just after this work, Ikoma [7] reported privately the occurence of the transient photocapacitance overshoot behaviour typical of EL2 in LPE ion implanted layers prepared just as Martin et al. [21]. This clearly demonstrates the creation of EL2 by ion implantation and annealing in both bulk and LPE materials. Consequently, it appears clearly that EL2 is an intrinsic defect associated level.

In fact, the situation seems a little more complicated because the team of Tokyo University reported differences in the Arrhenius activation energies of the electron emission rate, in the photoionization threshold and also in the photoquenching spectra for midgap levels created by different methods (oxygen implantation, LEC growth, Horizontal Bridgman growth and MOCVD layers) $[19,20]$. To interpret these data, Ikoma et al. [22, 23] have introduced the concept of «EL2 family » EL2 would not be a unique defect.

Another important idea is the electron hopping mechanism between defects concentrated in clusters after implantation [16, 24]. After preliminary experiments at LEP [7], Langlade et al. [24] published detailed DLTS data on electronic defects introduced by boron ion implantation in $\mathrm{n}-\mathrm{GaAs}$. The DLTS spectra observed as can be seen in figure 1 consists of a wide peaks referred to as the $U$ band which is approximately centered between the peak of the well-known EL6 and EL2 electron trap levels. Similar spectra have also been observed with GaAs Schottky barrier diodes when the surface state density is large $[25,26]$ and also in neutron irradiated samples (see following sub-section) [16]. Initially, the $U$ peak has been associated to a band of defects [27]. Several characteristics features were pointed out by Langlade et al. [24] such as the electric field sensitivity dependence on the annealing temperature and a direct relationship between the $U$ band and EL2. Langlade et al. [24] and Martin et al. [16] have suggested that EL2 may be either isolated giving rise to the EL2 DLTS peak or surrounded by shallower electron traps at various distances which modify its electrical properties. The continuous change of the emission kinetics, giving rise to $U$ band, is explained by a phonon assisted tunnelling process between defects. These results were recently confirmed by

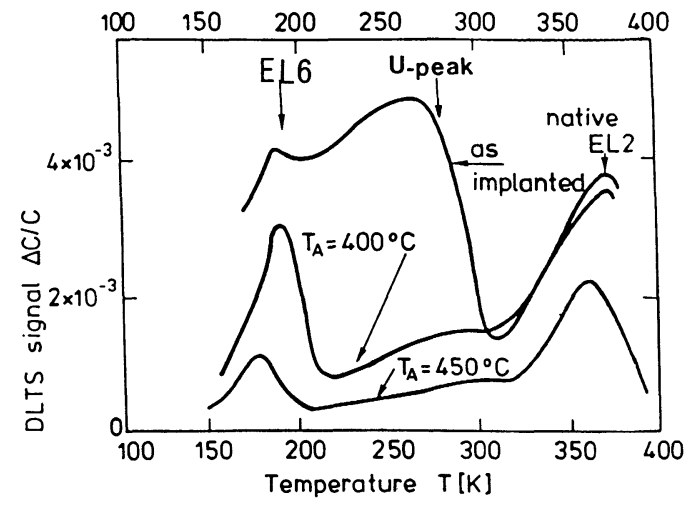

Fig. 1. - DLTS spectra for boron ion implanted n-GaAs (energy $=100 \mathrm{keV}$, dose $=10^{10} \mathrm{~cm}^{-2}$ ) after $30 \mathrm{~min}$ isochronal annealing at different temperatures. In the starting material, the free electron concentration was about $10^{17} \mathrm{~cm}^{-3}$. Gold Schottky diodes were used. The reverse bias voltage and the filling bias pulse amplitude were both 2 volts; the DLTS emission rate window was $7.5 \mathrm{~s}^{-1}$. After reference [24].

Samitier et al. [28, 29] who developped a new technique labelled Optical Isothermal Spectroscopy (OITS) based on the time analysis of the isothermal phototransients. The experimental optical data obtained on $\mathrm{n}$-GaAs implanted with boron and annealed at different temperatures show only the presence of the EL2 and EL6 levels. They are in complete agreement with the existence of an electronic interaction between these two deep traps $[28,29]$.

2.2 CREATION OF EL2 BY FAST NEUTRON IRRADIATION. - In GaAs extensive work trying to link $\mathrm{As}_{\mathrm{Ga}}$ antisites, EL2 defect and neutron damage has been carried out using mainly EPR and DLTS techniques. These studies followed the observation by EPR that the $\mathrm{As}_{\mathrm{Ga}}$ antisite could be introduced by fast neutron irradiation in GaAs [30].

2.2.1 DLTS results on neutron irradiated GaAs. Fast neutron irradiation should give similar results compared to ion implantation and actually DLTS spectra related to electron traps created by ion implantation or neutron irradiation are very similar. The first attempts were that of Martin et al. [16]. They reported about bulk n-type materials still conductive after irradiation with a dose of neutron of $3 \times 10^{15} \mathrm{n}^{\circ} \mathrm{cm}^{-2}$. Prior to irradiation, the wafers were annealed at $870{ }^{\circ} \mathrm{C}$ under $\mathrm{Si}_{3} \mathrm{~N}_{4}$ capping in order to strongly reduce the EL2 concentration in the surface depletion region down to $(3-5) \times$ $10^{14} \mathrm{~cm}^{-3}$.

Before annealing electron emission DLTS spectra are dominated by the EL6 level $\left(E_{\mathrm{C}}-0.35 \mathrm{eV}\right)$ and by a wide peak near room temperature around $E_{\mathrm{C}}-0.5 \mathrm{eV}$ which is referred as the $\mathrm{U}$ band [16]. In these experiments, the concentration of EL2 around 
$4 \times 10^{14} \mathrm{~cm}^{-3}$ after the thermal treatment to clear the EL2 level is more than one order of magnitude smaller than that of the $U$ band and seems not to be distinctly increased by the irradiation. After annealing has been carried out by isochronal anneals (30 $\mathrm{min})$ at increasing higher temperature $(400,450$, 500 and $600{ }^{\circ} \mathrm{C}$ ) the DLTS peak position of the U band is observed to vanish and to gradually shift towards EL2 ; it becomes coincident with EL2 for annealing temperatures above $550^{\circ} \mathrm{C}$ [16] (Fig. 2).

$\triangle C / C$ OLTS SIGNAL

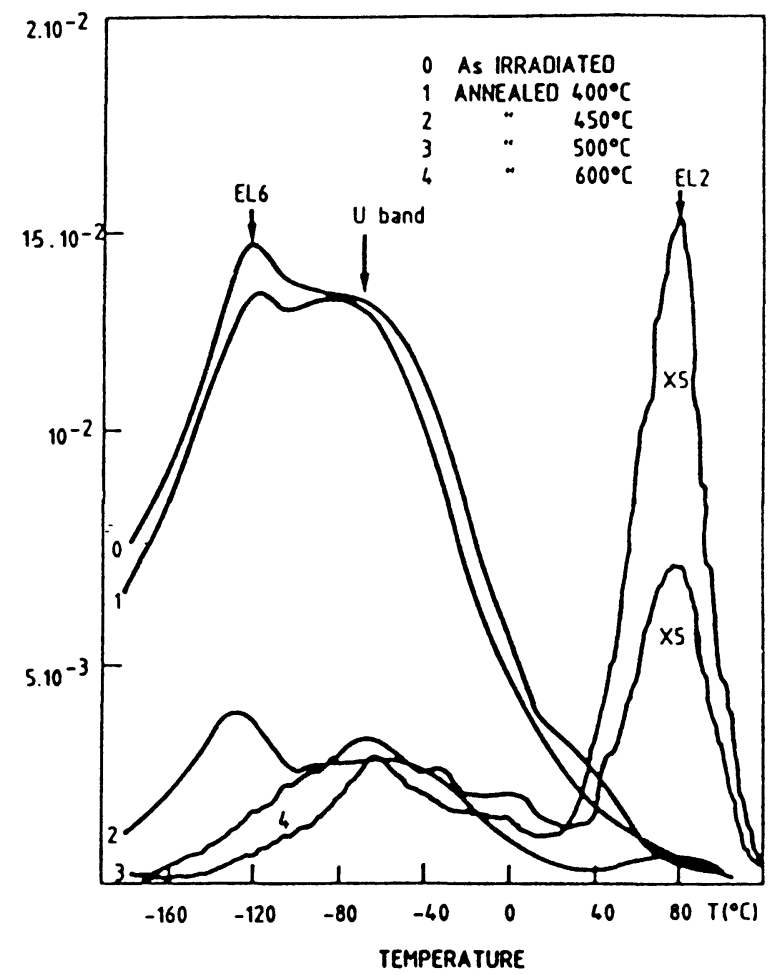

Fig. 2. - DLTS spectra for fast neutron irradiated nGaAs (dose $=3.1 \times 10^{15} \mathrm{~cm}^{-2}$ ) as irradiated and after $15 \mathrm{~min}$ isochronal annealing at different temperatures. In the starting material the free electron concentration was $1.8 \times 10^{17} \mathrm{~cm}^{-2}$. Gold Schottky diodes were used. The DLTS emission rate window was $7.5 \mathrm{~s}^{-1}$. The thickness of the investigated region below the surface $2000 \pm 400 \AA$. After reference [16].

The annealing kinetics of the EL6 level and U band are studied : it is found that EL6 vanishes by a pair defect (short-range) recombination while the $U$ band anneals by a long-range migration process. The concentration of the deep donor level EL2 is found to increase (Fig. 3) in the temperature range between $400{ }^{\circ} \mathrm{C}$ and $500{ }^{\circ} \mathrm{C}$ where most of the other defects corresponding to the $\mathrm{U}$ band are annealed. Similar experiments have been repeated by Magno et al. [31], Barnes et al. [32] and Guillot et al. [33] using LPE materials which contain no electron trap present before irradiation. Two broad bands of defects, $U$ and $\mathrm{L}$, roughly peaking at $E_{\mathrm{C}}-0.55 \mathrm{eV}$ and

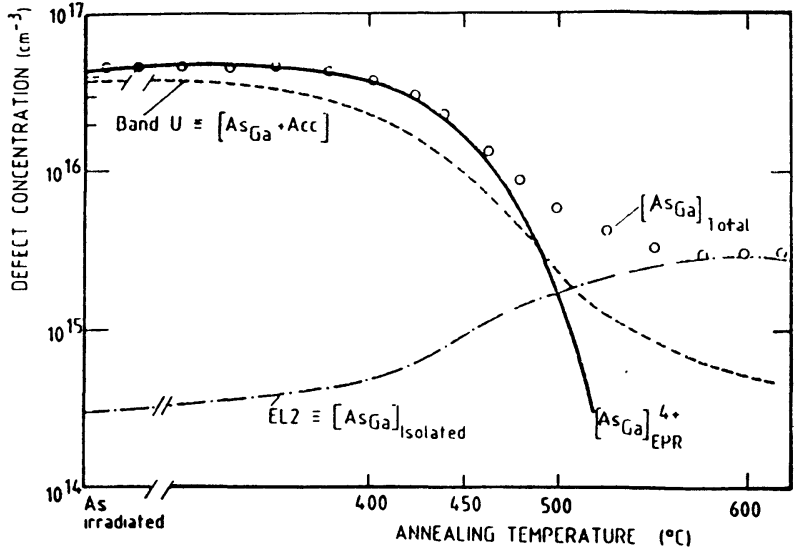

Fig. 3. - Variation of the DLTS concentration of the EL2 level and of the $U$ band created by irradiation with a neutron dose of $3 \times 10^{15} \mathrm{~cm}^{-2}$ as a function of the annealing temperature (annealing time : $15 \mathrm{~min}$; doping level of the starting unirradiated material $=1.5 \times$ $10^{17} \mathrm{~cm}^{-3}$ ). The material used is a bulk material previously annealed at $870^{\circ} \mathrm{C}$ in order to deplete the surface region from EL2 traps. Open circles are supposed to correspond to the total concentration of the EL2 defect (EL2 isolated $+U$ band). The full line represents variation of the concentration of the $\mathrm{As}_{\mathrm{Ga}}$ defect detected by EPR after fast neutron irradiation in $\mathrm{n}-\mathrm{GaAs}$ and isochronal annealing. An assignment is proposed for each of the defect ; $\left[\mathrm{As}_{\mathrm{Ga}}\right]$ isolated means a defect with $\mathrm{As}_{\mathrm{Ga}}$ as a core which does not interact with another defect. After reference [7, $16,30]$.

$E_{\mathrm{V}}+0.7 \mathrm{eV}$ respectively have been detected by Barnes [32] and Guillot [33] with introduction rate estimated to be about $5 \mathrm{~cm}^{-1}$ for low fluence $\left(<5 \times 10^{14} \mathrm{n}^{\circ} \mathrm{cm}^{-2}\right)$. Guillot et al. [33] have detected the creation of EL2 after irradiation before annealing with an introduction rate of about $0.15 \mathrm{~cm}^{-1}$. Moreover, the photoquenching effect has been found at $77 \mathrm{~K}$ with an amplitude corresponding to the EL2 concentration detected by DLTS [33] (Fig. 4).

This result shows that EL2 is created in as-irradiated $\mathrm{GaAs}$ samples by fast neutron with a small introduction rate.

Defects produced by fast neutron irradiation at room temperature in n-type vapor phase epitaxy $\mathrm{GaAs}_{1-x} \mathrm{P}_{x}$ alloys have also been studied by DLTS [34]. A broad midgap band due to a majority carrier trap similar to the $U$ band has been detected. Photocapacitance quenching has also been observed on this band at low temperature. Consequently, these authors concluded that the generated midgap centre detected by DLTS belongs to the EL2 family. In fact, we underline that only a small fraction of the EL2 related DLTS peak amplitude shows the photoquenching behaviour as we have found for $\mathrm{GaAs}$ [35]. 


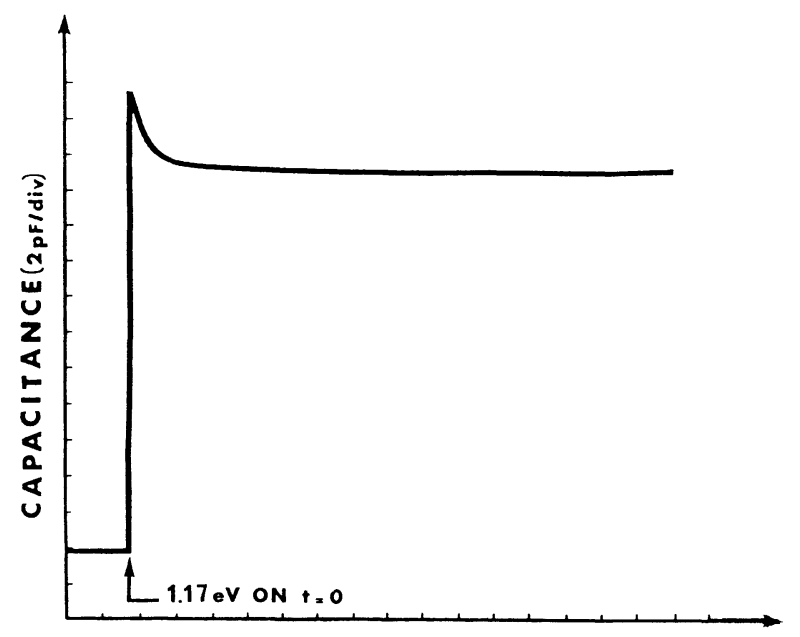

TIME(60sec/div)

Fig. 4. - Photocapacitance quenching effect at $77 \mathrm{~K}$ related to the presence of the EL2 defect in n-type LPE GaAs layers irradiated with fast neutron at $300 \mathrm{~K}$ $\left(\right.$ dose $\left.=6 \times 10^{14} \mathrm{~cm}^{-2}\right)$. After reference [33].

2.2.2 EPR observations in neutron irradiated. EPR is certainly one of the most powerful technique to give detailed informations about the microscopic identification of defects in semiconductors. Anion antisite defects $\left(\mathrm{As}_{\mathrm{Ga}}\right)$ were the first intrinsic native lattice defects identified by EPR in as-grown SI GaAs [36]. Then, it was shown that the same EPR signal can be enhanced by electron irradiation [37], by neutron irradiation $[30,38]$ or by plastic deformation [39]. Figure 5 shows EPR spectra of the characteristic $\mathrm{As}_{\mathrm{Ga}}^{4+}$ quadruplet $(\mathrm{Q})$ observed in asgrown, plastically deformed and in neutron ir-

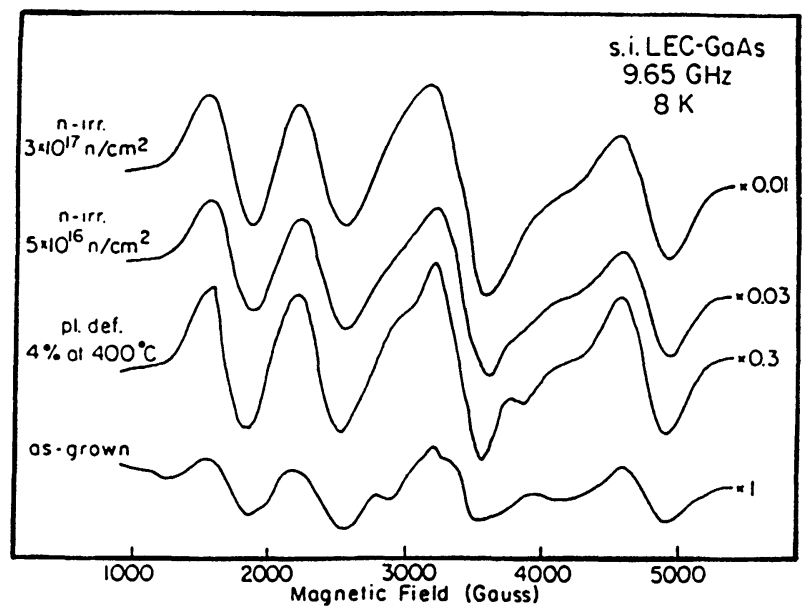

Fig. 5. - EPR spectra of $\mathrm{As}_{\mathrm{Ga}}^{4+}$ in as-grown, plastically deformed and $\mathrm{n}$-irradiated $\mathrm{GaAs}$. The $\mathrm{As}_{\mathrm{Ga}}^{4+}$ concentrations range from $5 \times 10^{15} \mathrm{~cm}^{-3}$ (as-grown) to $1 \times$ $10^{15} \mathrm{~cm}^{-3}$ (as-grown) to $1 \times 10^{18} \mathrm{~cm}^{-3}\left(3 \times 10^{17} \mathrm{n} / \mathrm{cm}^{2}\right)$. The spectra in as-grown and plastically deformed samples were taken with a computer for background subtraction. After reference [5]. radiated SI LEC GaAs. A very important remark for the identification problem which has caused a lot of confusion in the literature during the last four years is the following. The hyperfine interactions of large magnitude cannot be resolved because in GaAs all the host elements have nuclear spin greater than 1 and the linewidths are large compared with the superhyperfine splitting [40]. Consequently, in the case of such broad lines it is not possible to distinguish from EPR measurements alone if the defect has perfect tetrahedral symmetry like the isolated antisite $\left(\mathrm{As}_{\mathrm{Ga}} \mathrm{As}_{4}\right)$ or if it is weakly distorted by another defect beyond the first shell of As atoms since in this case most of the EPR parameters would only be slightly affected. So, EPR measurements give equivalent spectra for the isolated antisite $\left(A s_{\mathrm{Ga}}\right)$ and for the antisite in complex form $\left(\mathrm{As}_{\mathrm{Ga}}+\mathrm{X}\right)$ where the effect of the nearby defect $\mathrm{X}$ cannot be resolved. In this case $\mathrm{As}_{\mathrm{Ga}}$ is only the core or a more complex defect which gives rise to the observed EPR spectra. So, when speaking of the EPR As $\mathrm{Aa}_{\mathrm{Ga}}$ signal this corresponds to all the defects having $\mathrm{As}_{\mathrm{Ga}}$ as a core and more than one centre can produce very similar EPR spectra. One way to distinguish between them is then to look at their behaviour under $1.1 \mathrm{eV}$ photoexcitation: the grown-in or stress induced centres are quenchable [9], while those generated by neutron irradiation are not $[30,41]$. Optically detected electron nuclear double resonance (ODENDOR) investigations on as-grown SI GaAs confirmed this lack of resolution of the classical EPR because they revealed the presence of additionnal arsenic antisites with a different symmetry but a similar concentration as the isolated $\mathrm{As}_{\mathrm{Ga}} \mathrm{As}_{4}$ centres [42].

For fast neutron irradiations, the EPR $\mathrm{As}_{\mathrm{Ga}}$ defect introduction rate was found to be $10 \mathrm{~cm}^{-1}$ for small neutron fluxes of about $10^{11} \mathrm{n}^{\circ} \mathrm{cm}^{-2} \mathrm{~s}^{-1}$ [38] and to $3 \mathrm{~cm}^{-1}$ for neutron fluxes larger than $10^{13} \mathrm{~cm}^{-2} \mathrm{~s}^{-1}$ [30]. This yield is similar to the introduction rate of the $U$ band in DLTS experiments [16, 32]. A detailed analysis of the EPR spectra of neutron irradiated samples show that they consist in two main features : namely a quadruplet $\mathrm{Q}$ ascribed to $\mathrm{As}_{\mathrm{Ga}}^{4+}$ like but also a singlet $S$ near $g=2$ which has been suggested to be "vacancy-like " and tentatively attributed to $\mathrm{V}_{\mathrm{Ga}}^{-2}$ [43]. The two spectra grow in strength linearly with neutron fluence up to a final dose of $2.5 \times$ $10^{17} \mathrm{n}^{\circ} \mathrm{cm}^{-2}$ [44] irrespective of the sample type. It was found that the quadruplet and the singlet lines have closely correlated temperature dependences with similar deviations from the expected CurieWeiss law at about $100 \mathrm{~K}$ [43]. Evidence that the two defects are interacting is also given by the thermal variation of the hyperfine constant with increasing temperature [45]. These results were taken as evidence that these two defects are associated and that both the $S$ and $Q$ lines are generated within the same 
complex of intrinsic nature. Goltzene et al. [46, 47] concluded that the neutron irradiation induces essentially $\mathrm{As}_{\mathrm{Ga}}$ and $\mathrm{V}_{\mathrm{Ga}}$ centres interacting in a whole family of complexes of $\mathrm{As}_{\mathrm{Ga}}-\mathrm{V}_{\mathrm{Ga}}$ type where the relevant parameter is likely their distance. The results of thermal annealing of the $\mathrm{As}_{\mathrm{Ga}}^{4+}$ spectrum in as-grown, neutron irradiated and plastically deformed GaAs have been discussed by Weber [48] and Kaufman et al. [49]. Whereas the EPR quadruplet signal is thermally stable up to $950{ }^{\circ} \mathrm{C}$ in asgrown materials [49] it is found to anneal as from a temperature of $450{ }^{\circ} \mathrm{C}$ in neutron irradiated (or in plastically deformed) materials [48]. This behaviour points to a complex nature for this defect and confirms again than more than one centre can produce very similar EPR spectra.

Figure 6 shows the intensity variation of the two irradiation induced EPR signals, the quadruplet and singlet lines as function of isochronal annealing steps. The $\mathrm{S}$ line disappears completely at $450{ }^{\circ} \mathrm{C}$ while only some $90 \%$ of the initial intensity of the quadruplet has decayed at $600^{\circ} \mathrm{C}$, the remaining signal being observable until $850^{\circ} \mathrm{C}$ [45]. The thermal behaviour of the $S$ and $Q$ lines are very similar to that of the EL6 and U DLTS peak respectively [16] (Fig. 3).

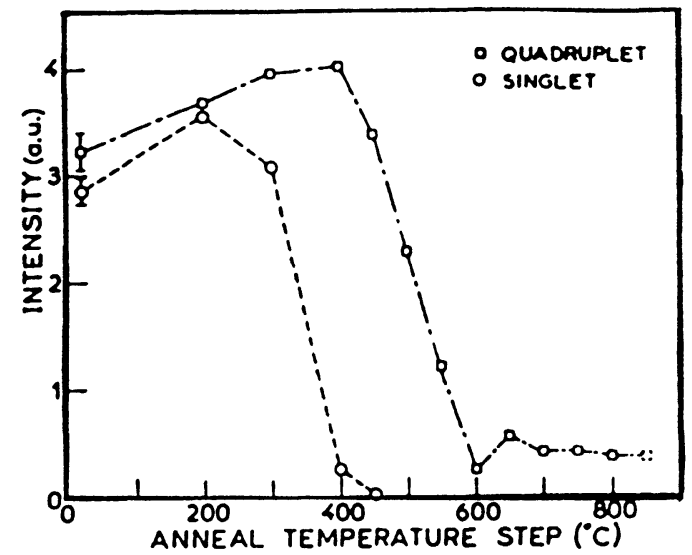

Fig. 6. - Variation of the intensities of fast neutron generated EPR quadruplet and singlet respectively corresponding to $\mathrm{As}_{\mathrm{Ga}}^{4+}$ and $\mathrm{V}_{\mathrm{Ga}}^{2-}$ versus annealing temperature. After reference [45].

Recently, Beall et al. [50] reported the EPR studies on GaAs samples irradiated with fast neutrons up to very large doses $\left(10^{20} \mathrm{n}^{\circ} \mathrm{cm}^{-2}\right)$. Their results are in rather good agreement with those of Goltzene et al. $[38,45]$ presented just above. However, the dose dependance they found for the $Q$ and $S$ spectra imply that the $S$ defects are located in the core region of disordered material whereas the $\mathrm{Q}$ centres must be located both in the cores and the surroundings shells of less-heavily damaged material [50].
While the identification of the $Q$ spectrum with the EPR $\mathrm{As}_{\mathrm{Ga}}$ antisite is clear, the $\mathrm{S}$ spectrum is difficult to identify because of the lack of resolved hyperfine structure [50,51]. The Strasbourg group attributed tentatively the $S$ line to a gallium vacancy [43]. A similar broad EPR spectrum with the same $g$ value was also observed in electron-irradiated GaAs [46]. It should be noted however that there is no evidence of damage defects in the gallium sublattice [14] and consequently it must be emphasized that a definitive interpretation of the $S$ spectrum has not been achieved. It could arises from groups of close $\mathrm{As}_{\mathrm{Ga}}$ defects in which the electrons are coupled by exchange interactions [50,52]. Furthermore, Baraff $e t$ al. [53] point out that the RPE spectrum of $\mathrm{As}_{\mathrm{i}}$ could be mistaken for a gallium vacancy.

\subsubsection{Correlation of EPR and DLTS measurements.} We are left with three identification problems : what is the nature of the $U$ band, the Q EPR signal ? What is the defect responsible for the EL2 DLTS peak ? It is reasonable to identify the Q EPR signal to the isolated antisite $\mathrm{As}_{\mathrm{Ga}}$ or to a more complex structure of the form $\mathrm{As}_{\mathrm{Ga}}+\mathrm{X}, \mathrm{X}$ being some unknown second-neighbour defect (perhaps the $S$ line defect).

Since both the EPR $A s_{\mathrm{Ga}}$ defect and the $\mathrm{U}$ band have similar creation rate and also the same annealing behaviour, it has been proposed that the $U$ band, and not the EL2 DLTS peak, could be associated with the EPR defect [7].

As already mentionned in section 2.2.1 in order to interpret coherently all the main results, Martin et al. [16] and Langlade et al. [24] make the assumption that the $U$ band is the EL2 level in disguise : it represents the EL2 trap interacting electrically with shallower traps. These authors underlined that in analysing defects created by fast neutron irradiation or ion implantation, it is essential to correctly interpret and predict the effects of Coulomb's interaction and of the important overlap of the electronic wave functions of the different localized states created in the defect clusters which favours interdefect electron tunnelling transitions. This assumption seems particularly plausible because for low doses, each primary neutron collision results in the displacements of about a thousand atoms and a highly disordered core region is generated with an average radius of about $50 \AA$ [54]. The concentration of defects around the core tails off within a wider defective region of a radius of about $200 \AA$ outside of which only a low concentration of point defects is present in the matrix [54]. Experimental evidence for the existence and extended size of these regions was found several years ago in GaAs [55].

The following assumptions have been proposed on this basis :

- EL2 is supposedly created by irradiation and 
corresponds to the $\mathrm{As}_{\mathrm{Ga}} \mathrm{EPR}$ detected defect $\left(\mathrm{As}_{\mathrm{Ga}}\right.$ or $\left.\mathrm{As}_{\mathrm{Ga}}+\mathrm{X}\right)$

- the electrical and optical properties of EL2 are completely transformed within the defect clusters by surrounding shallower level (like EL6). An electron trapped on a EL2 created defect could either be directly emitted or make first a hopping step to a nearby shallower electron trap by a multiphonon tunnelling process before being emitted. The tunnelling probabilities are greatly enhanced for high density defect clusters because of the small effective mass for the conduction band in GaAs. The broad U DLTS peak is due to the wide statistical distribution of the hopping time constant between the two defects which is explained by the random distribution of tunnelling lengths involved. This gives rise to very non-exponential electron emission transients. For high annealing temperature, the average defect separation increases and so do the hopping time constant values. This results in isolated defect behaviour as observed experimentally by the fact that the U DLTS peak position gradually shifts towards EL2 by isochronal anneal at increasing temperatures and becomes coincident with EL2 for annealing temperatures above $550{ }^{\circ} \mathrm{C}[16,24,29]$. However, the interacting defects would be located sufficiently apart from EL2 and not in the nearest neighbour shell in such a way that the Q EPR signal is hardly modified.

These assumptions can explain almost all the experimental data (Fig. 3). In this model, the $U$ band defects correspond to the $\mathrm{As}_{\mathrm{Ga}} \mathrm{EPR}$ defect interacting with another defect and its concentration is similar to the EPR As ${ }_{\mathrm{Ga}}$ defect. The electrical and optical properties of this trap (supposed to the EL2 defect) is very large which leads to an important shift and widening of the EL2 DLTS peak and to a disappearance of the photoquenching behaviour since the major part of the $\mathrm{As}_{\mathrm{Ga}}$ defect created by neutron irradiation is no longer quenchable. At very small doses, a few created EL2 defect are isolated and we have detected them with the known EL2 like electrical and optical properties [33]. During the annealing stage IV (between $400-500{ }^{\circ} \mathrm{C}$ ) most of the interacting defects like EL6 disappear and above $500{ }^{\circ} \mathrm{C}$, most of the remaining $\mathrm{As}_{\mathrm{Ga}}$ become isolated and are detected as the EL2 DLTS peak. In the same temperature range some EPR $\mathrm{As}_{\mathrm{Ga}}$ defects disappear by an unknown mechanism which would explain why the total concentration of EL2 $\left(\mathrm{EPR} \mathrm{As} \mathrm{Ga}_{\mathrm{G}}+\mathrm{EL} 2\right.$ isolated) slightly decreases (Fig. 3).

\subsection{ELECTRON IRRADIATION EXPERIMENTS.}

2.3.1 Is EL2 created by electron irradiation at room and higher temperature? - The defects created by electron irradiation in $\mathrm{n}$ and $\mathrm{p}$ type GaAs have been extensively studied [14]. From all the experimental results concerning defect creation (versus the energy of irradiation, temperature, doping concentration, nature of the material, crystalline orientation) and annealing (versus doping concentration, carrier injection) it is concluded that the defects produced by electron irradiation at room temperature and below are a distribution of vacancy-interstitial pairs in the As sublattice [14]. This is due to the fact that the $\mathrm{V}_{\mathrm{As}}$ vacancy and the $A s_{\mathrm{i}}$ interstitial remain practically immobile during irradiation in standard conditions (low doses, room temperature). The vacancy-interstitial pairs in the Ga sublattice recombine immediately after their creation [14].

Electron beam irradiation at room temperature and low doses $\left(<10^{16}\right.$ electrons $\left.\mathrm{cm}^{-2}\right)$ does not create EL2 in spite of the fact that a lot of different defects have been observed to be produced during that process [14]. The E4 level which appears in DLTS spectra at the position of EL2 $\left(E_{\mathrm{C}}-0.76 \mathrm{eV}\right)$ does not show metastable behaviour which is regarded as fingerprint of EL2.

Most of the primary defects attributed to displacement of As sublattice are observed to anneal in the so-called stage III at around $220^{\circ} \mathrm{C}$ [14]. In this stage III, practically all the pairs recombine and a little number of defects escape recombination. However, at room temperature, in some particular conditions namely high irradiation flux [56], the mobility of $A s_{i}$ is observed and complex defect involving impurities are detected using infrared absorption and EPR measurements. Brozel et al. [57], Woodhead et al. [58] and Beal et al. [59] have shown by looking at the localized vibrational modes of boron and carbon that complexes involving a boron (or a carbon) atom with an interstitial $\mathrm{As}_{\mathrm{i}}$ are formed in such conditions. The creation of antisites $\mathrm{As}_{\mathrm{Ga}}$ has also been observed [37, 59]. The reason for which $\mathrm{As}_{\mathrm{i}}$ becomes mobile during high dose irradiations is certainly related to the so-called recombination-enhanced mechanism. The concentration of injected carriers is high enough to cause such enhanced migration of $\mathrm{As}_{\mathrm{i}}$ during irradiation if the electron flux is large. Such conditions for the mobility of $\mathrm{As}_{\mathrm{i}}$ correspond to high irradiation doses which lead to a semi-insulating material where the resulting defects can no longer be studied by DLTS technique but by infrared optical absorption or EPR.

Now, how does one create the conditions for the $\mathrm{As}_{\mathrm{i}}$ mobility - and thus the possibility of complex defects creation - leading to a material which is not semi-insulating ? A simple way is to perform irradiation at high enough temperatures $\left(T \geqslant 300{ }^{\circ} \mathrm{C}\right)$ in order to favor diffusion of $\mathrm{As}_{\mathrm{i}}$ and then separation of each of the defects forming the primary Frenkel pair $\left(\mathrm{V}_{\mathrm{As}}-\mathrm{As}_{\mathrm{i}}\right)$ with respect to its local recombination. Recently, Stievenard et al. [60,61] and Bencherifa et al. [62] performed such experiments using electron 
and proton irradiations respectively. These authors observed after electron or proton irradiation at about $300{ }^{\circ} \mathrm{C}$ a series of new traps in concentration considerably larger than the concentration of $P$ traps which remain after stage III annealing [14]. Furthermore, this concentration increases with increasing temperatures as expected [61]. Stievenard et al. [61] used LEC and VPE materials while Bencherifa $e t$ al. [62] used LPE layers free of electron traps. Theses studies show that these traps are complex defects because they are depending on the material. Nevertheless two of them have thermal signatures identical to the ones of two native defects, namely EL2 and EL5. On this basis Stievenard et al. [61] claimed that EL2 is created in n-type GaAs (LEC and VPE) by electron irradiation at high temperature. In fact, these authors have not checked whether this defect exhibits the EL2 metastable state property. Bencherifa et al. [62] made some complementary optical measurements on this trap and found no photoquenching behaviour at all. We can conclude that EL2 is not created during high temperature irradiation. However, a defect having exactly the same electrical properties as EL2 but exhibiting no photoquenching effect is created by preventing recombination of Frenkel pair generated in the As sublattice. Perhaps this defect belongs to the EL2 family.

These observations allow simply to conclude that EL2 is nor a simple primary defect neither a complex defect formed by interaction of a primary defect with an impurity contained in the material.

2.3.2 Creation of arsenic antisite $\mathrm{As}_{\mathrm{Ga}}$ by electron irradiation. - Because of the consensus emerging now among both experimentalists and theorists that EL2 is a complex involving an arsenic antisite defect $\left(\mathrm{As}_{\mathrm{Ga}}\right)$ as one of its constituents, it is important to speak about the generation of $\mathrm{As}_{\mathrm{Ga}}$ antisites by electron irradiation because this could be the first step in the EL2 artificial formation.

EPR studies have shown that the arsenic antisite defect, $\mathrm{As}_{\mathrm{Ga}}$ is present as native defect in SI GaAs materials in the $10^{16} \mathrm{~cm}^{-3}$ concentration range [13, $36,63,64]$ and that its intensity is proportional to the $\mathrm{EL}^{+}$(defect in its single positive charge state) concentration. Photoquenching and enhancement of the antisite spectrum show clear similarities with the optical cross sections of EL2 [13] which provides a further link between EL2 and $\mathrm{As}_{\mathrm{Ga}}$. Let us bear in mind however that because of the large line widths, it is very unlikely that effect of nearby defects can be resolved $[30,40]$. If so $\mathrm{As}_{\mathrm{Ga}}$ is only the core of a more complex defect which gives rise to the observed EPR signal. So by EPR As $\mathrm{As}_{\mathrm{Ga}}$ signal it can be referring either to an isolated or to a more complex defect $\left(\mathrm{As}_{\mathrm{Ga}}+\mathrm{X}\right)$ like the EPR signatures of these defects will be the same provide $\mathrm{X}$ does not change too much the wave function of $\mathrm{As}_{\mathrm{Ga}}$ in the complex.
Contrary to the $\mathrm{As}_{\mathrm{Ga}}$ defect observed by RPE in as grown semi-insulating samples which is related to the $\mathrm{EL2}^{+}$defect, the $\mathrm{As}_{\mathrm{Ga}}$ level formed by electron irradiation shows no photoinduced metastable behaviour [65]. Recently, this property was used cleverly by von Bardeleben $e t$ al. [66] and Stievenard et al. [67] to show that EPR measurements coupled with $1.1 \mathrm{eV}$ photoexcitation in semi-insulating materials containing $\mathrm{As}_{\mathrm{Ga}}$ created by electron irradiation are able to differentiate two types of defect in the spectrum associated with the antisite (Fig. 7) : one created by the irradiation which is stable under photoexcitation, i.e. the isolate $\mathrm{As}_{\mathrm{Ga}}$ and another one metastable, i.e. EL2 preexisting in the material. These authors clearly show in this first step that EL2 is a complex of the type $\left(\mathrm{As}_{\mathrm{Ga}}+\mathrm{X}\right)$. In the following steps, they show that $\mathrm{X}$ is an interstitial arsenic atom nearby [65-67].
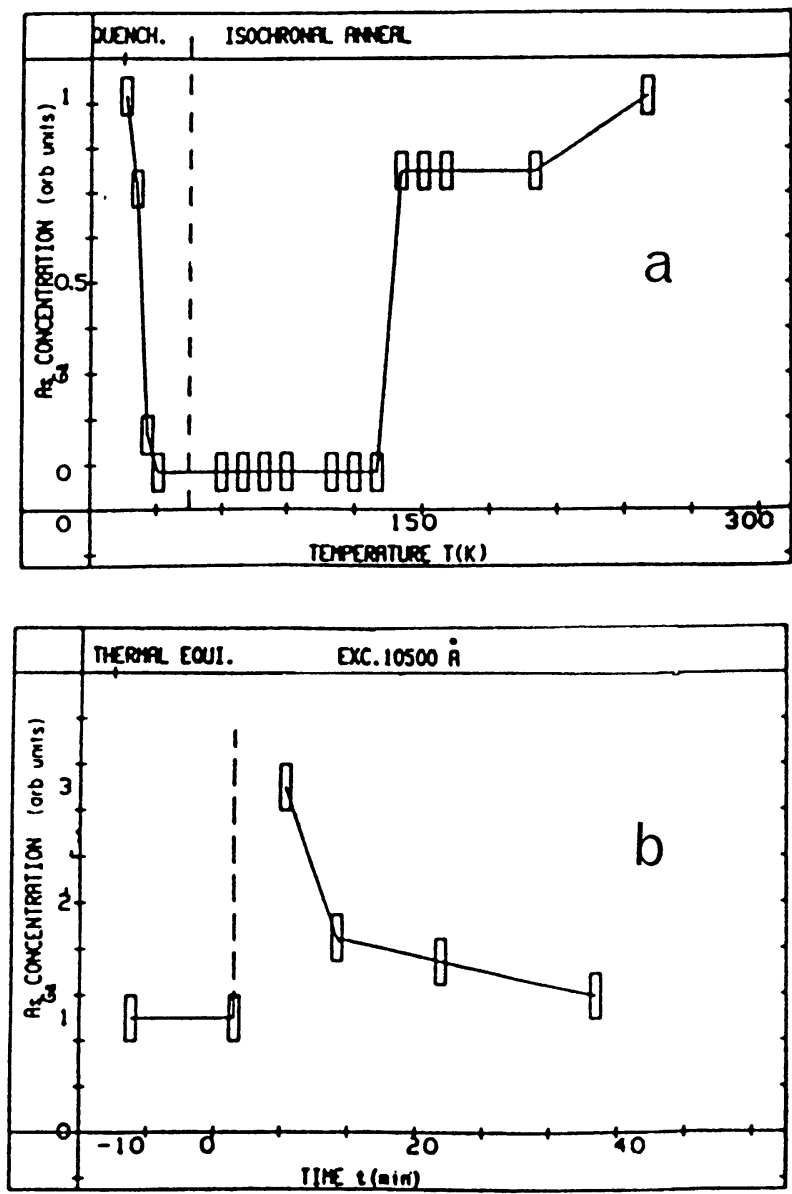

Fig. 7. - a) Variation of the antisite concentration (detected by EPR) induced by $1.1 \mathrm{eV}$ photoquenching and subsequent thermal annealing in a as-grown semi-insulating GaAs material. b) Variation of the antisite concentration (detected by EPR) versus time in a semi-insulating, irradiated, material following $1.1 \mathrm{eV}$ photoexcitation. The electron irradiation $\left(7 \times 10^{17} \mathrm{~cm}^{-2}, 1 \mathrm{MeV}\right)$ introduces $\sim 10^{16} \mathrm{~cm}^{-3} \mathrm{As}_{\mathrm{Ga}}$ which present no photoquenching effect compared to the $\mathrm{As}_{\mathrm{Ga}}$ (EL2) EPR native defects. After reference [66]. 
The $\mathrm{As}_{\mathrm{Ga}}$ antisite was first detected following room temperature electron irradiation with large dose by Kennedy et al. in p-type material [68] and subsequently in n-type material by Goswami et al. [37] with a higher concentration $\left(\sim 10^{18} \mathrm{~cm}^{-3}\right)$. The EPR $\mathrm{As}_{\mathrm{Ga}}$ introduction rate is very different in $\mathrm{n}$ type material (between 1 and $10 \mathrm{~cm}^{-1}$ ) and on semiinsulating or p-type material $\left(\sim 10^{-2} \mathrm{~cm}^{-1}\right)[69,70]$.

Different models have been proposed to account for the creation of $\mathrm{As}_{\mathrm{Ga}}$ defects by electron irradiation. They are largely discussed in the review paper of Pons et al. [14] and very recently by von Bardeleben et al. [71]. Let us summarize them briefly. They can be classified into two groups :

i) in the first the antisite defect is directly created by electron irradiation. For example, Kennedy et al. [68] proposed a model based on the recombination of primary defects $\mathrm{V}_{\mathrm{Ga}}$ and $\mathrm{As}_{\mathrm{i}}$ and von Bardeleben et al. [70] proposed a mechanism based on carrier recombination enhanced mobile arsenic interstitials exchanging sites with gallium-substituted impurities

ii) in the second group, the $\mathrm{As}_{\mathrm{Ga}}$ defect is already present in the as-grown material complexed with vacancies $\left(\mathrm{As}_{\mathrm{Ga}}-\mathrm{V}_{\mathrm{Ga}}\right)$ and the formation of isolated $\mathrm{As}_{\mathrm{Ga}}$ defects is due to the capture of $\mathrm{Ga}$ interstitials which were assumed to be created by the irradiation and to be mobile in the irradiation conditions [37, 59, 72]. This model is mainly based on the observation that the $\mathrm{As}_{\mathrm{Ga}}$ defect was observed to be produced before the B-As $s_{i}$ complex defect began to grow. These authors $[37,59,72]$ attributed the existence of electron dose thresholds for the complex defect formation to a mobility variation of the interstitial ions induced by a shift of the Fermi level. This interpretation is however apparently in contradiction with the main results which are known for the electron irradiation defects [14] : i) most of the created defects are associated with displacements in the As sublattice, ii) their introduction rate are independent of the Fermi level position, iii) the $A s_{i}$ mobility is recombination enhanced.

Very recently, von Bardeleben et al. [71] proposed another model for $\mathrm{As}_{\mathrm{Ga}}$ creation in n-type $\mathrm{GaAs}$ by electron irradiation. This model is stated on the assessment of a new defect attributed to a complex of an arsenic antisite defect and an arsenic vacancy on a nearest-neighbour position, $\mathrm{As}_{\mathrm{Ga}} \mathrm{As}_{3} \mathrm{~V}_{\mathrm{As}}$, formed in the early stage of irradiation [73]. From its introduction rate $\left(\sim 1 \mathrm{~cm}^{-1}\right)$ as well as its formation by electrons with an energy close to the threshold of $250 \mathrm{keV}$ for a single atomic displacement, this defect is assumed to be the stable transformed atomic configuration of the gallium vacancy $\mathrm{V}_{\mathrm{Ga}}$ in $\mathrm{n}$-type GaAs. It is then the precursor defect of the isolated antisite defect $\mathrm{As}_{\mathrm{Ga}} \mathrm{As}_{4}$ which is subsequently formed by the trapping of a mobile arsenic interstitial $\mathrm{As}_{\mathrm{i}}$.
This $\mathrm{As}_{\mathrm{Ga}}$ formation mechanism would be dominant in n-type GaAs explaining the high introduction rate of this defect in such a material. In this precursor defect is no longer created - due to a shift of Fermi level which can lead to either the structural stability of the $\mathrm{V}_{\mathrm{Ga}}$ or to immediate recombination of the Ga Frenkel pairs - other formation mechanisms such as the exchange one [70] which certainly have a much lower introduction rate can become predominant. This would be the case in semi-insulating or p-type material.

As a consequence of this $\mathrm{As}_{\mathrm{Ga}}$ formation model and in the hypothesis of a complex of the form $\mathrm{As}_{\mathrm{Ga}}+\mathrm{As}_{\mathrm{i}}$ as demonstrated by von Bardeleben et al. [66], the first step of the EL2 formation under electron irradiation would be the formation of $\mathrm{As}_{\mathrm{Ga}}$ isolated antisite by the $\mathrm{As}_{\mathrm{i}}$ mobility due to the energy liberated by the recombination of electronhole pairs produced by the irradiation on the $\mathrm{As}_{\mathrm{i}}$ site. The duration of irradiation must be large enough to induce a sufficient diffusion length of $A s_{i}$ to allow interaction of $\mathrm{As}_{\mathrm{i}}$ with precursor defects. Subsequently, the creation of EL2 requires the trapping of another arsenic interstitial by the $\mathrm{As}_{\mathrm{Ga}}$ formed in the first step. So, the overall formation process of EL2 requires the successive trapping of two interstitials which certainly gives a very small introduction rate for EL2. This explains why there is no evidence of the EL2 creation with a detectable concentration after electron irradiation at room temperature or a higher temperature either by DLTS experiments (at low doses) or by EPR measurements (at large doses).

2.3.3 Creation of complexes involving EL2. Another new idea which has been developped to interpret the $U$ band in neutron or implanted samples is to say : EL2 is created but its electrical (DLTS peak) and optical properties are completely modified by the presence of surrounding defects. This model was first introduced by the LEP team $[16,24]$ to account for observations in heavy-particle bombarded materials where it is known that defect clusters are produced. Very recently, MakramEbeid et al. proposed an extended version of their model even to electron irradiated materials $[74,75$, 76]. They have developped a quantum mechanical model for the calculation of the electron phononassisted inter-defect tunnelling transition rate between defects having deep energy levels in the band gap $[75,76]$. Using this theory for fast electron irradiated n-GaAs, they have attributed the observed high-temperature DLTS peaks (E4 and E5) to defect pairs each including the EL2 midgap donor $\left(\mathrm{As}_{\mathrm{Ga}}\right.$ or $\mathrm{As}_{\mathrm{Ga}}+\mathrm{X}$ ) together with one of the acceptors (E2 and E3 respectively) which are both related to $\left(\mathrm{V}_{\mathrm{As}}-\mathrm{As}_{\mathrm{i}}\right)$ [14]. Each component of the pair is separated by a distance $r$. 
This inter-distance is assumed to be small enough (up to $100 \AA$ ) to permit multiphonon tunnelling transitions. The observed DLTS peaks of the E4 and E5 defects together with the strong sensitivity to the electric field for E5 are satisfactorily simulated in electron irradiated n-GaAs. Moreover, the DLTS behaviour of the damage clusters occuring in heavy particle bombarded materials is like-wise simulated and only the individual defects (E1, E2, E3 and EL2, E1 and E2 being two charge states of the same defect) are sufficient to account for the electrical behaviour. Again the DLTS peak position and their large sensitivity to the electric fields are correctly simulated. Using the same nearest-neighbour interdefect electron hopping model, Makram-Ebeid $e t$ al . $[75,76]$ obtain a very good agreement between experimental results on the damage induced electrical conductivity and theoretical calculations.

The important conclusion of this study is that one should be very cautious in interpreting the frequently observed slight changes in DLTS peak positions and shapes between different materials. Long range defect interaction (up to $100 \AA$ ) can strongly influence the DLTS peaks and such interactions can give rise to a family of defects with not exactly the same properties.

From the model of Makram-Ebeid et al. [76] the EL2 defect should be created directly by electron or heavy-particle irradiation at room temperature in normal conditions of doses, the interaction with other shallow defects preventing it to be detected by its normal DLTS peak. The consequence of that is that the metastability property of EL2 must also have completely disappeared because of the pairing since no photoquenching effect is found for E4 and E5 levels. The main objection to this model is, however, that after stage III corresponding to the recombination of close Frenkel pairs attributed to E1, E2 and E3, EL2 would then appear with its known electrical and optical properties. This has never been observed as far as we know.

\section{Discussion.}

All the experimental data presented give some very important answers to the basic question : what is the exact microscopic nature of EL2 ? but they also give rise to several other questions : when (and how) is it created? directly during irradiation or during annealing? what is the nature of other levels created by irradiation or appearing during annealing stages (EL6 for example)?

3.1 NATURE OF THE EL2 DEFECT. - From artificial creation experiments by irradiation, there are important definite conclusions :

1) EL2 is not related to an impurity [21, 22].

2) EL2 is not a primary intrinsic defect but a more complex one $[14,21]$.
3) EL2 certainly involves an anionic antisite defect $\mathrm{As}_{\mathrm{Ga}}$ since its concentration is large in materials grown under As-rich conditions and EL2 and $\mathrm{As}_{\mathrm{Ga}}$ EPR defects occur in similar concentration in as-grown SI GaAs [13, 36, 63].

4) EL2 EPR spectrum in the ground configuration is remarkably close to that of the isolated $\mathrm{As}_{\mathrm{Ga}}$ antisite but the two defects can be distinguished by their EPR photoquenching behaviour: EL2 is quenchable while $\mathrm{As}_{\mathrm{Ga}}$ isolated is not $[65,66]$.

5) EL2 is not the $\mathrm{As}_{\mathrm{Ga}}$ isolated antisite and it is a more complex defect involving $\mathrm{As}_{\mathrm{Ga}}$ as a core : $\mathrm{As}_{\mathrm{Ga}}+\mathrm{As}_{\mathrm{i}}[65,66]$.

This last assumption is in very good agreement with both EPR $[43,72]$ and ODENDOR results $[77,80]$ which provide strong evidence that $\mathrm{As}_{\mathrm{Ga}}$ defects are present as complexes with other lattice defects in first or second neighbour sites. Furthermore, EPR-tagged magnetic circular dichroism measurements show the different intracenter electronic transitions for the isolated $\mathrm{As}_{\mathrm{Ga}}$ and EL2 [80].

6) To explain the origin of the $U$ band in implanted and neutron irradiated n-type GaAs, Martin et al. [16] and Langlade et al. [24] have introduced a new and important idea : the electronic interaction between EL2 and other surrounding defects. The EL2 level may either be isolated giving rise to the classical EL2 DLTS or surrounded by shallower electron traps at various distances which modify considerably its electrical properties. The $\mathrm{U}$ band can be explained assuming the existence of a transition due to a phonon assisted tunnelling process giving a continuous change of the emission kinetics. This mechanism allows the transitions between EL2 and the nearby shallow traps depending on the applied electric field and the defect separation, which depends on the annealing process [16, 24]. This assumption can be used as well to explain the fluctuations of the EL2 electrical and optical properties observed in various samples. They have lead to the growing consensus that EL2 is not a unique defect but a family of related complexes which would be characterized by different defects for the $X$ part of the EL2 complex, for example $\left(\mathrm{As}_{\mathrm{Ga}}+\mathrm{X}\right)$. An alternative explanation to account for differences in photoionization, thermal ionization and photoquenching time constants would be the interactions with other surrounding defects. Usually observed variety of midgap levels classified in "EL2 family " may be alternatively explained by various EL2-other defect interactions according to their different separations. This would also explain why in the case of cluster defects created in neutron irradiation where the interactions can be very important, a major part of the EL2 centres introduced does not present the usual photoquenching behaviour [33].

Recently, various models for EL2 have been proposed all with $\mathrm{As}_{\mathrm{Ga}}$ as a core such as : i) $\mathrm{As}_{\mathrm{Ga}}$ 
vacancy complexes: $\mathrm{As}_{\mathrm{Ga}}-\mathrm{V}_{\mathrm{As}}[81,82]$ or $\mathrm{As}_{\mathrm{Ga}}{ }^{-}$ $\mathrm{V}_{\mathrm{As}}-\mathrm{V}_{\mathrm{Ga}}[83,84]$; ii) As aggregates [23] ; iii) $\mathrm{As}_{\mathrm{Ga}}-$ arsenic interstitial complex : $\mathrm{As}_{\mathrm{Ga}}-\mathrm{As}_{\mathrm{i}}[65,66]$. We whish only to underline here that the most plausible microscopic model of EL2 which does seem to account for much of what is known experimentally is that of von Bardeleben et al. $[65,66]$ namely : $\mathrm{As}_{\mathrm{Ga}}+\mathrm{As}_{\mathrm{i}}$ with $\mathrm{As}_{\mathrm{i}}$ in second-neighbour position of $\mathrm{As}_{\mathrm{Ga}}$ for the ground state while the metastable state corresponds to $\mathrm{As}_{\mathrm{i}}$ in first-neighbour position. $\mathrm{Re}$ cent additional supports for this model have been provided independently by ENDOR measurements which are consistent with an arsenic interstitial along the (111) axis from the antisite at a distance of the order of two bond lengths [85] and by uniaxial stress experiments on the photocapacitance quenching phenomenon which show directly that the EL2 defect is a complex with $\mathrm{C}_{3 \mathrm{v}}$ (trigonal) site symmetry [86].

This model does not come simply only from irradiation defect studies but it is rather in agreement with all the main experimental data obtained by such studies.

\subsection{WHEN AND HOW EL2 IS CREATED BY IRRADIA-} TION? - EL2 seems to be not created directly by electron irradiation at room or more higher temperature but it is introduced when the mass (and energy) of the particle is important enough to displace a large number of lattice atoms, i.e. to produce clusters of defects. The question is then : is the EL2 level created during the ion (or neutron) irradiation itselft or is it formed during the annealing stage IV ? This is indeed a very complicated problem since the exact defect creation mechanisms by heavy particles are far from being understood.

Ikoma et al. [18] proposed that EL2 appears at the stage IV of annealing between 400 and $500{ }^{\circ} \mathrm{C}$ during which clusters of native defects created by heavy particle irradiation dissociate and migrate to form more stable forms. In fact, these authors cannot detect EL2 directly after ion implantation because their material becomes highly resistive due to the large doses used and the DLTS measurements cannot give valuable informations.

From results on neutron irradiated LPE GaAs $[16,33]$, it seems that EL2 is created directly during the irradiation itself and that only a very small part can be detected as EL2-like because it will appear in another form due to its electrical properties modified [16].

Makram-Ebeid et al. [74-76] proposed that EL2 is created directly by electron irradiation in normal conditions. They attribute the high temperature DLTS peaks E4 and E5 in fast electron bombarded $\mathrm{n}$-GaAs to distant defect-pairs involving the EL2 donor level together with shallower related acceptor levels assigned to $\mathrm{V}_{\mathrm{As}}-\mathrm{As}_{\mathrm{i}}$ Frenkel pairs (E2 and E3).
These authors also interpret DLTS and DC electrical conductivity results by the same individual intrinsic defects (EL2, E2, E3) grouped in dense damage clusters [74-76].

This assumption is alluring nut there is no direct experimental evidence of the direct creation of EL2 by electron irradiation in normal conditions while for small doses neutron irradiation there is $[14,33]$.

3.3 DisCuSSION ABOUT OTHER DEEP LEVELS. One may ask the question what electron trap corresponds to the isolated $\mathrm{As}_{\mathrm{Ga}}$ defect ? This level does not appear clearly in the DLTS spectra observed by von Bardeleben et al. [66] when following their hypothesis the EL2 complex $\left(\mathrm{As}_{\mathrm{Ga}}+\mathrm{As}_{\mathrm{i}}\right)$ is broken into its two components: $\mathrm{As}_{\mathrm{Ga}}$ isolated and $\mathrm{As}_{\mathrm{i}}$. Their result would tend to prove that this level has a very small capture cross section for electrons and consequently would be undetectable in standard conditions of DLTS experiments [56].

A second question concerns the nature of the EL6 level $\left(E_{\mathrm{C}}-0.35 \mathrm{eV}\right)$. It is a very common electron trap existing in both LEC and Bridgman materials with sometimes a concentration higher than EL2 $[22,87]$. The increase of this level has been observed to be greater than that of EL2 when applying As pressure [22]. EL6 and EL2 have very similar photoionization cross section $\sigma_{n}^{0}(h \nu)$ curve in the photon energy range $0.7-1.2 \mathrm{eV}$ as pointed out by Chantre et al. [88]. It presents an abnormally lattice relaxation effect [88] EL6 is also produced by neutron irradiation and ion implantation $[16,28]$ and disappears by a short-range recombination during subsequent thermal annealing above $400{ }^{\circ} \mathrm{C}$ [16] while at the same time the EL2 concentration increases (Fig. 3). Its DLTS peak removal is well correlated with the disparition of the singlet line $S$ in the EPR spectra [45]. Furthermore, Wosinki et al. [89] observed very recently that plastic deformation of GaAs increased the concentration of EL6 traps while EL2 concentration is unchanged. They proposed tentatively that EL6 level is ascribed to isolated $\mathrm{As}_{\mathrm{Ga}}$ antisite [89]. The position of $\mathrm{As}_{\mathrm{Ga}}$ in the gap would then be in agreement with the expected position of the $0 /+$ level of the isolated antisite which has been independently proposed by von Bardeleben et al. [66] and Suezawa et al. [90, 91] to be situated between $0.30 \mathrm{eV}$ and $0.76 \mathrm{eV}$ from conduction band from independent experiments on the $\mathrm{As}_{\mathrm{Ga}}$ EPR signal observation as a function of the Fermi level variation.

However if the identification EL6 = isolated $\mathrm{As}_{\mathrm{Ga}}$ is correct one would expect an increase in the EL6 DLTS peak when EL2 defect is transformed into an isolated $\mathrm{As}_{\mathrm{Ga}}$ by a thermal treatment [66]. This is not the case and probably EL6 would note be due to an isolated $\mathrm{As}_{\mathrm{Ga}}$. It could perhaps be a more intrinsic complex defect. To be complete however 
we must present some very recent remarks of Makram-Ebeid et al. [76] : they proposed that in fact EL6 has an electron ionization activation energy almost identical with that of E3 $\left(E_{\mathrm{C}^{-}}-0.32 \mathrm{eV}\right.$ at $\left.0 \mathrm{~K}\right)$ and can be confused with it in DLTS experiments. The only way to differentiate the two defects is to measure their electric field dependence and their optical photoionization cross sections. Actually, these authors [76] reinterpret phonon assisted electron hopping rates between irradiation created deep levels by assuming interaction between EL2 and E3 (instead of E6 in previous results [16, 24]. More works are clearly needed on the exact identification of defects created by irradiation or implantation.

\section{Conclusion.}

In this paper, we have tried to review all the recent data about EL2-related studies in irradiated and implanted GaAs. A big step towards the identification of this level has been made using artificial creation of EL2 by irradiation with electrons or implantation with heavier particles (ions, neutron).
After a period of extreme confusion in the data due to the lack of coherence between EPR and DLTS results, it has been definitely established that EL2 is an intrinsic and complex lattice defect with an arsenic antisite $A s_{\mathrm{Ga}}$ as a core, certainly $\mathrm{As}_{\mathrm{Ga}}+\mathrm{As}_{\mathrm{i}}$ which is now the current consensus. The observed variety of EL2 properties might be associated with different trap distributions in various crystals and not with inherent properties of the traps themselves. If much more remains to be done to completely understand some obscure points (exact creation mechanism by heavy particles, electronic interactions between deep levels, stage IV of annealing,...) this proves the usefulness of irradiation defect studies by a combination of techniques (DLTS, EPR, ENDOR) in the very important problem of defect identification in semiconductors.

\section{Acknowledgements.}

The author would like to thank G. A. Baraff, T. Figielski, S. Makram-Ebeid and M. Levinson who have sent preprints of their works before publication.

\section{References}

[1] Bois, D. and Vincent, G., J. Phys. Lett. 38 (1977) 351.

[2] Vincent, G. and Bois, D., Solid State Commun. 27 (1978) 431.

[3] Vincent, G., Bois, D. and Chantre, A., J. Appl. Phys. 53 (1982) 3643.

[4] Makram-Ebeid, S., Langlade, P. and Martin, G. M., Proceedings of the Third Conf. on SI IIIV Materials (Shiva, Nantwhich England) 1985, 184.

[5] Weber, E. R. and OMLing, P., Festkorperprobleme (Advances in Solid State Physics) 25 (Vieweg, Braunschweig) 1985, p. 623.

[6] Gatos, H. C. and Lagowski, J., Mater. Res. Soc. Proc. 46 (1985) 153.

[7] Martin, G. M. and Makram-Ebeid, S., Deep Centers in Semiconductors, ed. by S. T. Pantelides (Gordon and Breach, New York) 1985, p. 399.

[8] Lin, L., Omelianovski, E. and Bube, R. H., J. Appl. Phys. 47 (1976) 1852.

[9] Weber, E, R., EnNen, H., KaufmanN, U., WINDSCHEIF, J., SCHNEIDER, J. and WoSINSKI, T., J. Appl. Phys. 53 (1982) 6140.

[10] Leyral, P., Vincent, G., Nouailhat, G. and Guillot, G., Solid State Commun. 42 (1982) 67.

[11] Martin, G. M., Appl. Phys. Lett. 39 (1981) 747.

[12] Lagowski, J., Gatos, H. C., Parsey, J. M., WaDA, K., KAMINSKA, M. and WALUKIEWICZ, Appl. Phys. Lett. 40 (1982) 342.

[13] Bauemler, M., KaUfMANN, U. and Windscheif, J., Appl. Phys. Lett. 46 (1985) 781.

[14] Pons, D. and Bourgoin, J. C., J. Phys. C. 18 (1985) 3839.
[15] LANG, D. V., Rad. Effects in Semiconductors, Inst. Phys. Conf. Ser. $n^{\circ} 31$ (1977) 70.

[16] Martin, G. M., Esteve, E., Langlade, P. and Makram-Ebeid, S., J. Appl. Phys. 56 (1984) 2655.

[17] JERVIS, T. R., WOODARD, D. W. and EASTMAN,L. F., Electron. Lett. 15 (1979) 621.

[18] IKoma, T., TAKIKAWA, M. and TANiguchi, M., Int. Conf. on GaAs and Rel. Cpds (Oiso, Japan) Inst. Phys. Conf. Ser. $n^{\circ} 63$ (1982) 191.

[19] Taniguchi, M. and Ikoma, T., Semi-Insulating III$V$ Materials (Evian) ed. by S. Makram-Ebeid and B. Tuck (Shiva Pub., Nantwich) 1982, p. 283.

[20] Taniguchi, M. and Iкoma, T., Int. Conf. on GaAs and Rel. Cpds (Albuquerque, USA) Inst. Phys. Conf. ser. $n^{\circ} 65$ (1983) 65.

[21] Martin, G. M., Terriac, P., Makram-Ebeid, S., Guillot, G. and Gavand, M., Appl. Phys. Lett. 42 (1983) 61.

[22] Iкомa, T., Taniguchi, M., MochizUKi, Y., Int. Conf. on GaAs and Rel. Cpds (Biarritz, France) Inst. Phys. Conf. ser. $n^{\circ} 74$ (1985) 65.

[23] Iкома, T. and Mochizuki, Y., Jpn J. Appl. Phys. 24 (1985) L 935.

[24] Langlade, P. and Makram-Ebeid, S., Proc. of the Int. Conf. on GaAs and Rel. Cpds (Biarritz, France) Inst. Conf. Ser. $n^{\circ} 74$ (1985) 281.

[25] Onuma, T., Venoyama, T. and Yagita, H., Appl. Phys. Lett. 44 (1984) 80.

[26] Yahata, A. and Nakajima, M., Jpn Appl. Phys. 23 (1984) L 313. 
[27] Martin, G. M. and Makram-Ebeid, S., Proceedings of the 12th ICDS (Amsterdam) Physica 116 B (1983) 371.

[28] Samitier, J., Morante, J. R., Giraudet, L. and Gourrier, S., Appl. Phys. Lett. 48 (1986) 1138.

[29] Samatier, J., Herms, A., Cornet, A., Morante, J. R., Gourrier, S., Phys. Scripta 35 (1987) 524.

[30] Worner, R., KaufmanN, U. and Schneider, J., Appl. Phys. Lett. 40 (1982) 141.

[31] Magno, R., SPencer, M., Giessner, J. G. and WEBER, E. R., Proc. of the 13th ICDS (Coronado, USA) ed. L. C. Kimmerling and J. M. Parsey, J. Electron. Mater. 14a (1985) 981.

[32] BARnes, C. E., Zipperian, T. E. and Dawson, L. R., J. Electron. Mater. 14 (1985) 95.

[33] Guillot, G., Bencherifa, A., NouAilhat, A., unpublished.

[34] Munoz, E., Garcia, F., Jimenez, B., Calleja, E., Gomez, A., Alcober, V., Appl. Phys. Lett. 47 (1985) 798.

[35] Garcia, F., Munoz, E., Calleja, E., Alcober, V., J. Electron. Mater. 15 (1986) 133.

[36] Wagner, R. J., Krebs, J. J., Strauss, G. H. and White, A. M., Solid State Commun. 36 (1980) 15.

[37] Goswami, N. K., Newman, R. C. and Whitehouse, J. E., Solid State Commun. 40 (1981) 473.

[38] Goltzene, A., Meyer, B. and Schawb, C., J. Appl. Phys. 54 (1983) 3117.

[39] Weber, E. R., Mat. Res. Soc. Symp., Eds N. M. Johnson, S. G. Bishop, G. D. Watkins 46 (1985) 169.

[40] Wilsey, N. D. and Kennedy, T. A., Mat. Res. Soc. Symp. vol. 46 (1985) 309.

[41] Wosik, J., Palczewska, M. and Kaminska, M., Acta Phys. Pol. A 69 (1986) 431.

[42] Hofmann, D. M., Meyer, B. K., Lohse, F. and SPAeth, J. M., Phys. Rev. Lett. 53 (1984) 1187.

[43] Goltzene, A., Meyer, B. and Schwab, C., Proc. of the 3rd Int. Conf. on SI III-V Materials (Kahnee-ta, USA) (Shiva, Nantwich) (1984) 291.

[44] Goltzene, A., Meyer, B., Schwab, C., GreenBAUM, S. G., WAGNER, R. J. and KENNEDY, T. A., J. Appl. Phys. 56 (1984) 3394.

[45] Goltzene, A., Meyer, B. and Schwab, C., J. Appl. Phys. 57 (1985) 1332.

[46] Goltzene, A., Meyer, B., Schwab, C., Beall, R. B., NeWman, R. C., Whitehouse, J. E. and Wood Head, J., J. Appl. Phys. 57 (1985) 5196.

[47] Goltzene, A., Meyer, B., Schwab, C., GreenBAUM, S. G. and WAGNeR, R. J., Proc. of the Int. Conf. on GaAs and Rel. Cpds (Biarritz, France), Inst. Phys. Conf. Ser. $n^{\circ} 74$ (1985) 35.

[48] Weber, E. R., Semi-Insulating III-V Materials, ed. D. C. Look and J. S. Blakemore (Shiva, Nantwich) (1984) 296.

[49] KaufmanN, U., Windscheiff, J., Bauemler, M., SCHNEIDER, J. and KoHL, F., Semi-Insulating III-V Materials, ed. D. C. Look and J. S. Blakemore (Shiva, Nantwich) (1984) 246.
[50] Beall, R. B., Newman, R. C. and Whitehouse, J. E., J. Phys. C. 19 (1986) 3745.

[51] Maguire, J., Newman, R. C. and Beall, R. B., J. Phys. C. 19 (1986) 1877.

[52] Kaczmarek, E., Defects in Semiconductors, ed. H. J. von Bardeleben, Materials Science Forum, vol. 10-12 (Trans. Tech. Pub., Switzerland) 1986, p. 253.

[53] Baraff, G. A. and Schluter, M., Phys. Rev. B 35 (1987) 6154.

[54] Contes, R. and Mitchell, E. W., Adv. Phys. 24 (1975) 293.

[55] Bertolotti, M., Papa, T., Sette, D. and Vitali, G., J. Appl. Phys. 38 (1967) 2645.

[56] Stievenard, D., Thèse de Doctorat d'Etat, Lille (1986).

[57] Brozel, M. R. and Newman, R. C., J. Phys. C. 11 (1978) 3135.

[58] Woodhead, J. and Newman, R. C., J. Phys. C. 14 (1981) L 345.

[59] Beall, R. B., Newman, R. C., Whitehouse, J. E. and Woodhead, J., J. Phys. C. 17 (1984) 2653.

[60] Stievenard, D., Bourgoin, J. C. and Pons, D., Proceedings of the 12th ICDS (Amsterdam, 1982) Physica B 116 (1983) 394.

[61] Stievenard, D. and Bourgoin, J. C., J. Appl. Phys. 59 (1986) 743.

[62] Bencherifa, A., Nouailhat, A. and Guillot, G., unpublished.

[63] Elliott, K., Chen, R. T., Greenbaum, S. G., Wagner, R. J., Appl. Phys. Lett. 44 (1984) 907.

[64] Tsukuda, N., Kikuta, T. and Ishida, K., Int. Conf. on GaAs and Rel. Cpds (Karuizawa, Japan) Inst. Phys. Conf. Ser. $n^{\circ} 79$ (1985) 205.

[65] von Bardeleben, H. J., Stievenard, D., DereSMES, D., Huber, A. and Bourgoin, J. C., Appl. Phys. Lett. 47 (1985) 970.

[66] von Bardeleben, H. J., Stievenard, D., DereSMES, D., Huber, A. and Bourgoin, J. C., Phys. Rev. B 34 (1986) 7192.

[67] Stievenard, D., von Bardeleben, H. J., BourGoIN, J. C. and Huber, A., Defects in Semiconductors, ed. H. J. von Bardeleben, Materials Science Forum, vol. 10-12 (Trans. Tech. Pub., Switzerland) 1986 , p. 305.

[68] Kennedy, T. A., Faraday, B. J. and Wilsey, N. D., Bull. Am. Phys. Soc. 26 (1981) 255.

[69] Beall, R. B., Murray, R., Newman, R. C. and Whitehouse, J. E., J. Phys. C. 18 (1985) L 763.

[70] von Bardeleben, H. J., Bourgoin, J.C., J. Appl. Phys. 58 (1985) 1041

[71] von Bardeleben, H. J., Miret, A., Lin, H. and Bourgoin, J. C., J. Phys. C. 20 (1987) 1353.

[72] Beal, R. B., Newman, R. C., Whitehouse, J. E. and Woodhead, J., J. Phys. C. 18 (1985) 3273.

[73] von BARDELEBEN, H. J., BouRgoIN, J. C. and Miret, A., Phys. Rev. B 34 (1986) 1360.

[74] Makram-Ebeid, S. and Boher, P., Defects in Semiconductors, ed. H. J. von Bardeleben, Materials Science Forum, vol. 10-12 (Trans. Techn. Pub., Switzerland) 1986, p. 1075. 
[75] Makram-Ebeid, S., Boher, P. and Lannoo, M., Appl. Phys. Lett. 50 (1987) 270.

[76] Makram-Ebeid, S., Boher, P. and Lannoo, M., to be published.

[77] Spaeth, J. M., Hofmann, D. M. and Meyer, B. K., MRS Conf. Symposium 46, ed. N. M. Jonhson, S. G. Bishop, G. C. Watkins (1985) 185.

[78] Meyer, B. K. and Spaeth, J. M., J. Phys. C. 18 (1985) L 99.

[79] Meyer, B. K., Hofmann, D. M., Spaeth, J. M. and LoHSE, F. : Inst. Conf. on Defects in Semiconductors (Coronado, USA) J. Electron. Mater. 14a (1985) 921.

[80] Meyer, B. K., Spaeth, J. M. and Sheffler, H., Phys. Rev. Lett. 52 (1984) 851.

[81] Lagowski, J., Kaminska, M., Parsey, J. M., Gatos, H. C. and Walukiewicz, W., Proc. of the Int. Conf. on GaAs and Rel. Cpds (Albuquerque, USA) Inst. Phys. Conf. Ser. $n^{\circ} 65$ (1983) 41.

[82] Baraff, G. A. and Schluter, M., Phys. Rev. Lett. 55 (1985) 2340.
[83] Zou, Y., ZhOU, J., Lu, Y., WANG, K., Hu, B., LU, B., LI, C. and SHAO, J., Proc. of 13th ICDS, J. Electron. Mater. 14a (1985) 1021.

[84] Wager, J. F. and Van Vechten, J. A., Phys. Rev. $B 35$ (1987) 2330 and references there in.

[85] Meyer, B. K., Hofmann, D. M. and Spaeth, J. M., Defects in Semiconductors, ed. H. J. von Bardeleben, Materials Science Forum, vol. 1012 (Trans. Techn. Pub., Switzerland) (1986) 311.

[86] Levinson, M. and Kafalas, J. A., to be published in Phys. Rev. B.

[87] Taniguchi, M. and Iкомa, T., J. Appl. Phys. 54 (1983) 6448.

[88] Chantre, A., Vincent, G. and Bois, D., Phys. Rev. B 23 (1981) 5335.

[89] Wosinski, T. and FigIELSKI, T., submitted to $J$. Appl. Phys.

[90] Suezawa, M., Hara, A. and Sumino, K., Acta Phys. Polo. A 69 (1986) 423.

[91] Suezawa, M. and Sumino, K., Jpn. J. Appl. Phys. 25 (1986) 553. 